\title{
Marriages, Polygamous, Early Fertility and Development in Congo
}

\author{
Diana Loubaki* \\ ISG, Department of Economics, University Marien NGouabi, Brazzaville, Congo \\ Email:diana.loubaki@laposte.net
}

How to cite this paper: Loubaki, D. (2017) Marriages, Polygamous, Early Fertility and Development in Congo. Journal of Human Resource and Sustainability Studies, 5, 193-213.

https://doi.org/10.4236/jhrss.2017.53018

Received: August 7, 2017

Accepted: September 26, 2017

Published: September 29, 2017

Copyright (c) 2017 by author and Scientific Research Publishing Inc. This work is licensed under the Creative Commons Attribution International License (CC BY 4.0).

http://creativecommons.org/licenses/by/4.0/

\section{c) (i) Open Access}

\begin{abstract}
This article uses endogenous growth theory to show that, both education and labor force participation of women are crucial mechanics of economic development. In an economic environment that prevailing polygamous and early fertility which yields inequalities among women, unemployed labor force is due to difficulties to ensure education for all the children born from different mothers. Thus increases of poverty create a feedback effect since the children's off-springs become also parental financial support. Indeed, introducing moral hazard and corruption in the economy due to absence of skills, thus information hold is not revealed in order to win money to support the big family. The article also shows that, social inheritance rule is modified, i.e., it may decrease a lot and yield to poverty trap and famine zone or may increase a lot and reach the highest levels or may converge depending on parental polygamous degree or remain equal to the parental status. Consequently, this article provides development foundations focused on women social promotion for development take-off in poorest countries.
\end{abstract}

\section{Keywords}

Moral Hazard, Social Status, Polygamous, Early Fertility, Marriages,

Inequality, Poverty, Corruption, Development, (JEL: I24, I25, I26, J12, J13, $\mathrm{J} 23, \mathrm{O} 11, \mathrm{O} 22)$

\section{Introduction}

Congo Republic is located in a center of Africa. According to Population Data.net, its population size in 2016 is evaluated up to 4,824,385 millions with an amount of per-capita GDP of 316,705 USD and per women fecundity rate is 4.68

*The Author wished to thanks the Editor for the Publication of this article and the Anonymous Referees for helpful comments. Any error which may appear in the text is due to the Author herself. 
children. After the war of 1997, men were killed and demographic composition became unbalanced in such a way that, women became higher than men are. Indeed, the government decided that, one man can have 1 to 4 wives. That decision has an impact on development and women social promotion, so that this article investigates in how far long-run growth can settled in that context added to other problems generated by polygamous like early fertility and poverty.

The analysis is conducted using an overlapping generation model or a macroeconomics discrete time model where people live during two periods of time, the agents are heterogeneous, i.e., some are college-educated and some others are not and some are men and some other are women. There is a marriage competitive market ruled by a marriage supply function provided by women and the marriage demand function provided by men, indeed, the equilibrium in wife choice exists since one curve is an increasing function and the other is a decreasing function. Women are chosen according to the quality function which increases with the education level attainment and decreases with fertility level (children hold) following the literature on the subject. The college-educated woman is the first lady of a given monogamous or polygamous college-educated man who chooses his wife at the second period after having accumulated human capital in contrast to the non-college educated agent who chooses his wife in the first period. At the long-run equilibrium, it yields women education and labor force participation is a mechanics of economic development since this fact is able to induce demographic transition, polygamous reduction and children quality increase. The girl (the teen-age) first period choice turns out to be going to college or being in pregnancy, thus to raise children in parental house which reduces parental income added to the polygamous choice, the financial charges become unsustainable. Therefore, the agent is unable to support education for all the children born from different mothers which becomes an accessory decision. That reality introduces changes in social status of the children in such a way that the inheritance rule is no more validated, because social regression is evident. Therefore, this article uses endogenous growth theory to promote both education and labor force participation of women in an economic environment that prevailing polygamous and early fertility which yields inequalities among women, thus creates an excess unemployed labor force caused by the difficulties to ensure education to all the children born from different mothers and poverty which creates a feedback effect, since the children face poverty and in order to fight against it, face early fecundity without marriage. Indeed, children off-springs become also parental financial support. Therefore, moral hazard and corruption are introduced in the economy due to absence of skills, thus information hold is not revealed in order to increase gain to support the big family. The whole modified social inheritance rule since social status becomes a dynamical process with several steps, i.e., it may decrease a lot and yield to poverty trap or may increase a lot and reach the highest levels or may converge depending on parental polygamous degree or remain equal to the parental status. Consequently, the edu- 
cated woman is the first lady in the educated man life, whereas the non educated woman face polygamous. Finally, the article provides development foundations focused on women social promotion in developing countries.

The scientific contribution of this article holds on several aspects: first, the model introduces both the literature of the link between education and marriage as well as gender differential in the endogenous growth analysis applied to developing countries; second, early fertility, polygamous and marriages components mostly viewed in empirical work are introduced in economic theory as mechanisms which slow development and increase poverty; third, there is sociological component in the explanation of development absence, i.e., social status is a mechanics of economic development rather than growth engines only.

The article introduces the literatures of poverty, moral hazard due to asymmetric information, inequality, the relation between education and marriages and the link between education and fertility inside the endogenous growth model added to components such as corruption, polygamous, social classes and early fertility. In the following, we briefly present the literature used.

The link between marriage and education is not well known yet in developing countries studies, the related literature still new and can be attributed to Regalia and Rios-Rull [1] which model features the heterogeneity between men and women focusing on the rise in the number of single women and suggest gender wage gap to be the main mechanism to explain this rise. Eckstein and Lifshitz [2] study the effect of the mechanics such that schooling, the gender wage gap, fertility, marriage and divorce has in the rise in female labor-force participation during the twentieth century. They find that up to 42 percent of the change is left unexplained, thus attributed this residual to household technology and changes in social norms. Greenwood, Seshari and Yorukoglu [3] analyze the importance of technological progress in the home sector to make easier the married women entry in the labor market. However, the importance of inequality and assortative mating has only been observed by Fernandez and Rogerson [4] as well as by Fernandez, Guner and Knowles [5]. Chiappori, Iyigun and Weiss [6] discuss how positive assortative mating provides a marriage market return for female educational investment. Greenwood et al. [7] study the relationship between assortative mating and household income inequality in a structural model, the goal of the paper is to develop a unified theory capable to explain marriages decline and divorce increase since 1960 in America. Therefore, our article is a theory of economic development since it adds some other components such that corruption, early fecundity, polygamous and social status phenomenon not studied in the standard literature focused on Western countries' marriages evolution. This article introduces to marriages vision in developing countries, specifically in Congo where it is composed of one man versus several women as well as early fertility deeply studied by Kremer and al in Kenya [8]. The article shows that under-development is also caused by women social regression since education is a social promotional engine in income aspect, thus protect against 
poverty.

The article is organized as follows: Section 2 sets up the model; Section 3 studies early fertility and its inconvenient; Section 4 studies polygamous cost; Section 5 studies marriages concepts; Section 6 studies moral hazard and corruption; Section 7 studies social status and development; Finally we conclude in Section 8 .

\section{The Model}

People marry for marital well-being and love in an economy where exist more women than men thus the government administration had decided that, one man can have 1 to 4 wives (Congo Republic Administration decision). But the men who are willing to have several wives, thus being polygamous need to earn an income higher than the equilibrium wage rate otherwise one wife only may be enough. The girls face early fertility risk i.e. may become mother under the age of 18 years old when enrolled in the high school or under that level when trained for a specific job. Indeed in an overlapping generation model where an agent live for two periods, the decision of the agents depends on the gender for example, a girl has to decide whether being married or get inside the education sector. Therefore, because she is too young to find a husband, if in pregnancy when living in parental house, without having someone to marry with she chooses to stay home to raise her baby and may have more than one baby while living with her parents, then remain non educated and face hidden unemployment, thus gets inside the excess unemployed labor category. Indeed, the girl's first period decision becomes only, being in pregnancy or getting inside the education sector and wait a little time to be a mother after a successful human capital accumulation period. Therefore, this reality introduces inequality among women in income and in consideration since the non educated woman face polygamous risk that we'll discuss later on in this paper. According to the major economic system, the man wins more than the woman because they are most of the time, endowed with a specific skill which allows that difference. Indeed, we assume the existence of an inequality in wage rate between the man and the woman in the labor market. Thus, the boy Decision depends on whether being skilled or not depending on his parental bequest that some of them receive in order to accumulate human capital in the education sector. Those who don't receive bequest can't get inside the education sector, thus get inside the production sector, therefore are unskilled in the first period and retired in the second period. More precisely, if the first period decision led to human capital accumulation inside the education system in order to be skilled later on while in the first period, the agent thus get married and have children only at the beginning of the second period when he begins to work. In contrast, the unskilled labor decision once taken, get married and have children in the first period and keep on having children during all his life since the wives he is going to take are always younger than before through the time. 
Because the both men agents have the opportunity to have 1 to 4 wives, men fertility increases, which decreases his per-capita income. Because the education of the children is costly, thus quantity choice reduces their quality [9] i.e., their future productivity, thus the firm's competition and finally, the economic growth rate of the nation since high level human capital becomes scarce added to moral hazard and corruption due to first the agents must look for income increase, thus don't reveal the information hold in the concern of their ability at work, second institutions are also endowed of agents who are looking for their wage income increase since multiple children as well as wives become too costly to support financially, thus are endowed of corrupted agents. Therefore, poverty faced by families endowed of many children as well as many wives for a single man, pushes per/capita income below the threshold yields moral hazard and corruption of institutions making the government intervention obvious in order to follow the law since the welfare theorem is no more validate, i.e., the equilibrium settled doesn't ensure Pareto optimality. Population growth rate moves according to $\frac{\left(N_{0}^{t+1}+N_{1}^{t+1}\right)-\left(N_{0}^{t}+N_{1}^{t}\right)}{\left(N_{0}^{t}+N_{1}^{t}\right)}=n_{0}^{t}+n_{1}^{t}$ where $n_{0}^{t}$ is population growth of the unskilled woman whereas, $n_{1}^{t}$ is population growth of the skilled woman indeed it is not high since we repertory that the average per-capita woman fecundity level is around 4 in Congo where $n_{0}^{t}>n_{1}^{t}, N_{0}^{t}$ is total non educated woman in the country and $N_{1}^{t}$ is total educated woman in the country where $N_{0}^{t}>N_{1}^{t}$. Some men and women are college-educated while some others are not college educated. Some individuals of each gender will be married with one woman only or polygamous or not married (this assumption is only retained for young girls who face early fecundity). A given man may marry one woman or more, the first woman who have been married to the male agent is called the first lady and is better seen than the second, the third or the fourth wife of that man and those second category women live outside of the main house because only the first "office" is allow to live there. All the marriages categories evocated have children and assume per-capita woman children number to be equal to 4 in average (statistic of fecundity in Congo), so that the polygamous man may have 15 children or more. A given agent faces an innate ability level, a (skill-biased technological change) ${ }^{1}$. The men aim is first, to accumulate human capital or not, indeed an uneducated man will earn the amount, $w_{0}=f(a)$ for each unit of labor supplied on the market while an educated man earn, $w_{1}=g(H)$ where $w_{1}>w_{0}$ for simplicity, we'll assume in the article, the wage rate income to be respectively only $W_{1}$ and $W_{0}$ and an educated woman earn a fraction $\theta_{1}$ of her educated husband income, similarly, the non educated woman live with her husband income and since $w_{1}, w_{0} \geq \bar{w}$ is the equilibrium of the wage rate income. Since the agent may be polygamous specifically when $w_{0} \geq \bar{w}$, the unskilled agent may have more than a single wife while the educated

\footnotetext{
${ }^{1}$ According to Romer (1990), the capital stock, $K$ is defined such that, $K=\sum_{i=1}^{\infty} \eta x_{i}=\eta \sum_{i=1}^{A} x_{i}=\eta A x$
} where $x_{i}=x$ for all $i \in N$ and $A$ is knowledge accumulated until a given period of time. 
man always has the opportunity to be polygamous since we always have $w_{1} \geq \bar{w}$ and if he is not willing to be such that sometimes because of some constraints like religious convictions, monogamous family preferences, and others cultural convictions, etc... Accumulation of human capital yields a direct cost, $u>0$ and $e$ denotes the fact that someone acquires education, thus $e \rightarrow 1$ then, $a \rightarrow 0$ meaning that he doesn't acquire education, indeed when $e \rightarrow 0$ then $a \rightarrow 1$.Second, the man has to choose his wife depending on several aspects gathered in what we call the wife quality, $q^{i}$ which depends positively on the education level attained ${ }^{2}$ and negatively on the fertility level $[10]^{3}$ i.e. the number of children she has such that the quality is an increasing function of education and a decreasing function of the number of children specifically for the first marriage. The educated agent receives a bequest, $B_{t}$ from his parents to accumulate human capital.

Following Cervellati and Sunde $[11]^{4}$, the quality of a given woman expressing the marriage demand curve is defined such that

$$
q_{t}^{i}=H_{t}^{1} \theta^{1}\left(1+g_{t+1}\right)-n_{t+1}^{1}+a_{t}-n_{t}^{0}
$$

where $H_{t}^{1}$ is human capital accumulation level, $\left(n_{t}^{0} \quad n_{t+1}^{1}\right)$ are the respective per-capita woman children number of the non educated and of the educated, $a_{t}^{i}$ is innate ability and $g_{t+1}$ is the economic growth rate

The woman offer of marriage depends on material well being and social quality aspects such that coming from high income families of the country acts on husband choice than we express by Equation (2) such that

$$
p_{t}^{i}=w_{0}^{t}+\frac{w_{1}^{t+1}}{R_{t+1}}
$$

where $i=0,1$ is the respective non educated and educated agents indexes. Equation (2) can be viewed in two different ways that is $p_{t}^{0}=w_{0}^{t}$ and $p_{t}^{1}=\frac{w_{1}^{t+1}}{R_{t+1}}$ which are the respective wealth of the non college-educated and the col${ }^{2}$ This paper develops a unified growth model that captures the historical evolution of population, technology, and output. It encompasses the endogenous transition between three regimes that have characterized economic development. The economy evolves from a Malthusian regime, where technological progress is slow and population growth prevents any sustained rise in income per capita, into a Post-Malthusian regime, where technological progress rises and population growth absorbs only part of output growth. Ultimately, a demographic transition reverses the positive relationship between income and population growth, and the economy enters a Modern Growth regime with reduced population growth and sustained income growth.

${ }^{3}$ According to Malthus (1798), sooner or later population gets checked by famine and disease offsetting population growth. He noticed that population grows at a geometric rate whereas food grows at an arithmetic rate only which led human catastrophe since it turns out to be to few to feed a growing population. Malthus point contradict Ester Boserup view of growth since population is an engine of economic development.

${ }^{4}$ This paper develops a quantifiable unified growth theory to investigate cross-country comparative development. The calibrated model can replicate the historical development dynamics in forerunner countries like Sweden and the patterns in cross-country panel data. The findings suggest a crucial role of the timing of the onset of the economic and demographic transition for explaining differences in development. Country-specific differences in extrinsic mortality are a candidate explanation for differences in the timing of the take-off across countries and the resulting worldwide comparative development patterns, including the bimodal distribution of the endogenous variables across countries 
lege-educated agents expressed by the respective per-capita wage rate income earned in the labor market. We assume that the non educated agents works in the first period and he is in rest in the second period [12] where he lives with his savings return, in contrast the educated agent earns his wage rate income in the second period only, therefore in the first period $p_{t}^{0}=w_{0}^{t}$ whereas in the second period, $p_{t}^{1}=\frac{w_{1}^{t+1}}{R_{t+1}}$. We don't include assets in the wealth of the agents since as we'll see it in this paper the men may have until 15 kids in average and may have one until four wives which introduce uncertainty on the assets inherited from parents in the way of having certain influence on the decision. But we assume that agents endowed of human capital level at initial time, leave a bequest to their off-springs to symbolize incentives to invest in human capital accumulation.

Indeed, we can determinate the marriage market equilibrium both for the educated and the non educated agents expressed by Equation (3) i.e.

$$
w_{0}^{t}+\frac{w_{i}^{t+1}}{R_{t+1}}=H_{t}^{1} \theta^{1}\left(1+g_{t+1}\right)-n_{t+1}^{1}+a_{t}-n_{t}^{0}
$$

Proposition 1: the non educated agent income is measured by his innate ability minus the number of children hold, $w_{0}^{t}=a_{t}-n_{t}^{0}$ in contrast, the educated agent income can be measured by the product of his human capital level, his wife income and the growth rate minus the number of children hold, $H_{t}^{1} \theta^{1}\left(1+g_{t+1}\right)-n_{t+1}^{1}$.

Proof: Equation (3) comes from the equalization of Equations (2) and (1) i.e. we set $p_{t}^{i}=q_{t}^{i}$. We can see that Equation (3) can be viewed in two different equations $w_{0}^{t}=a_{t}-n_{t}^{0}$ for the non educated agent and $\frac{w_{1}^{t+1}}{R_{t+1}}=H_{t}^{1} \theta^{1}\left(1+g_{t+1}\right)-n_{t+1}^{1}$ for the educated agent.

Following Greenwood and al, because the educated man chooses his wife according to some specific profiles, the non economic factors underlying a marriage consist on the respective compatibility represented by the function, $M\left(e, e^{*}\right)$ and $M\left(a, a^{*}\right)$ respectively for the educated and the non educated agents expressed by Equations (4) and (5) i.e.

$$
\begin{aligned}
& M\left(e, e^{*}\right)=\mu_{0}(1-e)\left(1-e^{*}\right)+\mu_{1}\left(e e^{*}\right)-n_{t+1}^{1} \\
& M\left(a, a^{*}\right)=\mu_{0}(1-a)\left(1-a^{*}\right)-n_{t}^{0}+\mu_{1}\left(a a^{*}\right)
\end{aligned}
$$

where $e$ is the fact that the male agent has acquired education and $e^{*}$ is the same thing for his wife. Similarly $a$ is the fact that the male agent didn't acquire education and $a^{*}$ is the same thing for his wife. Indeed if the educated couple in the marriage don't have the same education level, then $e \neq e^{\star}$ therefore

$M\left(e, e^{*}\right)=\mu_{0}(1-e)\left(1-e^{*}\right)-n_{t+1}^{1}$ otherwise, if the educated couple in the marriage have the same education level, then $e=e^{*}$ therefore

$M\left(e, e^{*}\right)=\mu_{1}\left(e e^{*}\right)-n_{t+1}^{1}$. Similarly if the non educated couple in the marriage 
don't have the same education level, then $a \neq a^{*}$ therefore $M\left(a, a^{*}\right)=\mu_{0}(1-a)\left(1-a^{*}\right)-n_{t}^{0}$ otherwise if the non educated couple in the marriage have the same education level, then $a=a^{*}$ therefore

$M\left(a, a^{*}\right)=\mu_{1}\left(a a^{*}\right)-n_{t}^{0}$. Consequently, the economic factors underpinning a marriage are based upon each person's ability, education attained and the number of children that is $\left(a, e, n_{t}^{0}, a^{*}, e^{*}, n_{t+1}^{1}\right)$ combination

Now suppose a married woman who stay at home whereas it still possible for her to go to school, the increased return to skill will entice more women to acquire education. The fact that there are more college educated men around implies that there may be a bigger incentive for women to invest in education in order to become more desirable on the marriage market because of compatibility considerations.

The production sector produces an homogenous consumption good with skills differentials i.e. there exist two production sectors called the high and the low sectors where the high production sector utilizes capital stock and educated agents such that

$$
Y_{t}^{H}=A_{t} K_{t}^{b} H_{t}^{1-b}
$$

where $b$ is the elasticity of capital stock in production function, $Y_{t}^{H}$ the high tech sector of production, $H_{t}$ is human capital stock and $A_{t}$ is technological change. Rewriting Equation (6) in intensive form yields per-capita production expressed such that

$$
y_{t}^{H}=A_{t} k_{t}^{b}
$$

where $k_{t}=K_{t} / H_{t}$ is the ratio of physical and human capital stock and $y_{t}^{H}=Y_{t}^{H} / H_{t}$ is per-capita production function of the firms

The low tech production function only uses non educated labor expressed such that

$$
Y_{t}^{L}=a \delta L_{t}
$$

Rewriting the above equation in intensive form yields

$$
y_{t}^{L}=a \delta
$$

where $y_{t}^{L}=Y_{t}^{L} / L_{t}$.

The first order conditions of the maximization problem of the firms yield the wage rate income of both the educated and the non educated labor forces as well as the interest rate such that

$$
\begin{gathered}
w_{1}^{t}=A_{t}(1-b) k_{t}^{b} \\
w_{0}^{t}=a \delta \\
R_{t}=A_{t} b k_{t}^{b-1}
\end{gathered}
$$

Proposition 2: economic performance, EP is provided by the product of the marriage couple human capital, $H_{t}^{1}$ his woman income, $\theta^{1}$ and technological change plus $1,1+g_{t+1}$ which equals to the product of the elasticity of human capital and physical, $(1-b) / b$ and per-capita capital dynamics, $k_{t+1}$ minus the number of children i.e. 


$$
H_{t}^{1} \theta^{1}\left(g_{t+1}+1\right)=\frac{(1-b)}{b} k_{t+1}-n_{t+1}^{1}
$$

Proof: according to Equations (10) and (11), we have $w_{0}^{t}=a \delta$ and $\frac{w_{1}^{t+1}}{R_{t+1}}=\frac{1-b}{b} k_{t+1}$ then according to Equation (3), $H_{t}^{1} \theta^{1}\left(1+g_{t+1}\right)-n_{t+1}^{1}+a_{t}-n_{t}^{0}=\frac{1-b}{b} k_{t+1}+a \delta$ which has two aspects: $a \delta=a_{t}-n_{t}^{0}$ and $\frac{1-b}{b} k_{t+1}=H_{t}^{1} \theta^{1}\left(1+g_{t+1}\right)-n_{t+1}^{1}$ meaning that the economic growth rate is essentially driven by incentives to invest in human capital accumulation measured by the elasticity of human capital, $b$ [13] whereas the number of children depresses the growth rate [14]. Therefore the economic performance is given by $E P=H_{t}^{1} \theta^{1}\left(g_{t+1}+1\right)=\frac{(1-b)}{b} k_{t+1}-n_{t+1}^{1}$.

Thus, this model promotes the work of the women as a mechanism of economic development and according to early development economists [15] [16] [17] [18] [19] $]^{5}$ the work of the women induces demographic transition since the cost of raising children becomes too high then reduces fecundity as well as raise the family income.

To close the model, we introduce the agents' preferences which are given by Equation (14) i.e.

$$
U^{i}=\ln \left(c_{t}^{i}\right)+\alpha \ln \left(c_{t+1}^{i}\right)+\beta \ln \left(n_{t+j}^{i}\right)
$$

where $j=0,1$ and $0<\beta, \alpha<1$ are parameters of the utility of having children and of being compatible, the utility of having children is highly positive in Congo so that it is an increasing function of the agent's utility. The educated marriage faces a tuition cost of education (direct and indirect), $u_{t}$ and first period consumption, $c_{t}^{i}$ since he receives a bequest from his parent, $B_{t}$ In the second period, the family spends his income on children raising activity which as a cost, $v w_{1}^{t+1}$ where $0<v<1$ after having seen their compatibility $M\left(e, e^{*}\right)$. Therefore, the budget constraint of the first period can be written such that $B_{t}=u_{t}+c_{t}^{1}$ and the second period budget constraint can be written such that $M\left(e, e^{*}\right) w_{1}^{t+1}\left(1+\theta_{1}-v\right) / R_{t+1}=c_{t+1}^{1} / R_{t+1}+B_{t}$ indeed the intertemporal budget constraint of the educated agent can be written such that

$c_{t}^{1}+\frac{c_{t+1}^{1}}{R_{t+1}}=M\left(e, e^{*}\right)\left(1+\theta^{1}-v\right) \frac{w_{1}^{t+1}}{R_{t+1}}-u_{t}+B_{t}+\Delta^{1}$

where $\Delta^{1}$ expresses others financial duties in the second period (we anticipate the following discussion in this paper on the cost of having several wives and children generated by the polygamous families).

Because $M\left(e, e^{*}\right)=\mu_{0}(1-e)\left(1-e^{*}\right)+\mu_{1}\left(e e^{*}\right)-n_{t+1}^{1}$ the previous constraint becomes,

${ }^{5}$ This author argued that the Industrial Revolution was caused by the Enlightenment, that is by the growth of science and Analytical thinking. 


$$
c_{t}^{1}+\frac{c_{t+1}^{1}}{R_{t+1}}=\left[\mu_{0}(1-e)\left(1-e^{*}\right)-n_{t+1}^{1}+\mu_{1}\left(e e^{*}\right)\right]\left(1+\theta^{1}-v\right) \frac{w_{1}^{t+1}}{R_{t+1}}-u_{t}+B_{t}-\Delta^{1}
$$

Indeed, $c_{t}^{1}+\frac{c_{t+1}^{1}}{R_{t+1}}=\left[\rho-n_{t+1}^{1}\right]\left(1+\theta^{1}-v\right) \frac{w_{1}^{t+1}}{R_{t+1}}+\left(B-u_{t}-\Delta^{1}\right)$

where $\rho-n_{t+1}^{1}=\mu_{0}(1-e)\left(1-e^{*}\right)+\mu_{1}\left(e e^{*}\right)$.

The non educated agent saves his money and raise children and support his wife financially, $r$ in the first period, he is in rest in the second period, thus consumes his savings. Indeed the budget constraints is expressed such that $(1-v-r) w_{0}^{t}=c_{t}^{0}+s_{t}$ in the first period whereas in the second period the agent consumes his savings returns such that, $c_{t+1}^{0}=R_{t+1} S_{t}-\Delta^{0}$ where $\Delta^{0}$ expresses the cost relates to family financial duties like keep on raising children without income as well as their offspring and other wives financial support. Therefore including the compatibility of the non educated agent hypothesis, it yields his intertemporal budget constraint such that, $c_{t}^{0}+\frac{c_{t+1}^{0}}{R_{t+1}}=\left(\bar{\rho}-n_{t}^{0}\right)(1-s-v) w_{0}^{t}-\frac{\Delta^{0}}{R_{t+1}}$ where $\bar{\rho}-n_{t}^{0}=\mu_{0}(1-a)\left(1-a^{*}\right)+\mu_{1}\left(a a^{*}\right)$.

The program of the individual agent consists on maximizing the utility function subject to the intertemporal budget constraints. Therefore the respective educated and non educated equilibrium values are given such that:

$$
\begin{gathered}
c_{t}^{1^{*}}=\left(\frac{1}{1+\alpha+\beta}\right)\left[\frac{\rho}{b}\left(1+\theta^{1}-v\right)(1-b) k_{t+1}+\left(B_{t}-u_{t}-\Delta^{1}\right)\right] \\
\frac{c_{t+1}^{1^{*}}}{R_{t+1}}=\left(\frac{\alpha}{1+\alpha+\beta}\right)\left[\frac{\rho}{b}\left(1+\theta^{1}-v\right)(1-b) k_{t+1}+\left(B_{t}-u_{t}-\Delta^{1}\right)\right] \\
n_{t+1}^{1^{*}}=\frac{\beta}{1+\alpha+\beta}\left[\rho+\frac{b\left(B-u_{t}-\Delta^{1}\right)}{\left(1+\theta^{1}-v\right)(1-b)} \frac{1}{k_{t+1}}\right]
\end{gathered}
$$

Indeed we can see that, the first period per-capita consumption is positively linked to per-capita physical capital as well as the bequest received which finally represent the agent first period income. In contrast, the main cost faced by the agent is family duties and the education cost. But family duties plays mostly in his second life period only, since he chooses to be married at that time, therefore it is quite low or inexistent in that time. The second period per-capita consumption function is thus, negatively linked to family duties which plays a great role now in contrast to education cost which was active before. But this function still positively correlated with the mechanisms previously quoted.

The optimal values of the non educated agent are given by the following equations

$$
\begin{aligned}
& c_{t}^{0}=\frac{1}{1+\alpha+\beta}\left[\bar{\rho}((1-s-v)) a \delta-\frac{\Delta^{0}}{R_{t+1}}\right] \\
& \frac{c_{t+1}^{0}}{R_{t+1}}=\frac{\alpha}{1+\alpha+\beta}\left[\bar{\rho}((1-s-v)) a \delta-\frac{\Delta^{0}}{R_{t+1}}\right]
\end{aligned}
$$




$$
n_{t}^{0}=\frac{\beta}{(1+\alpha+\beta)}\left[\bar{\rho}-\frac{\Delta^{0}}{a \delta(1-s-v) R_{t+1}}\right]
$$

Definition 1: the long run relative fecundity rate, $\bar{n}=\frac{n_{t+1}^{1}}{n_{t}^{0}}$ is defined by the locus on the space where all the variables are constant i.e. $R_{t+1}=R_{t}=R$, $u_{t}=u, A_{t+1}=A_{t}=A$ and $k_{t+1}=k_{t}=k$.

Proposition 3: according to Definition 1, the relative long run growth rate of the population, $\bar{n}$ is expressed such that,

$$
\bar{n}=\left[\rho+\frac{b\left(B-u-\Delta^{1}\right)}{\left(1+\theta^{1}-v\right)(1-b)} \frac{1}{k}\right] /\left[\bar{\rho}-\frac{\Delta^{0}}{a \delta b(1-s-v) A k^{b-1}}\right]
$$

Proof introducing Equations (16) and (19) inside the definition of the relative fecundity rate given above, we can determinate its expression i.e.

$$
\begin{gathered}
\bar{n}=\frac{n_{t+1}^{1}}{n_{t}^{0}}=\frac{n^{1}}{n^{0}}=\frac{\beta}{1+\alpha+\beta}\left[\rho+\frac{b\left(B-u-\Delta^{1}\right)}{\left(1+\theta^{1}-v\right)(1-b)} \frac{1}{k}\right] / \frac{\beta}{(1+\alpha+\beta)}\left[\bar{\rho}-\frac{\Delta^{0}}{a \delta(1-s-v) R}\right] \\
\text { Therefore, } \bar{n}=\left[\rho+\frac{b\left(B-u-\Delta^{1}\right)}{\left(1+\theta^{1}-v\right)(1-b)} \frac{1}{k}\right] /\left[\bar{\rho}-\frac{\Delta^{0}}{a \delta b(1-s-v) A k^{b-1}}\right]
\end{gathered}
$$
where $R=A b k^{b-1}$.

Definition 2: the balanced growth of the economy is defined by the locus on the space where $k_{t+1}=k_{t}=k, A_{t+1}=A_{t}=A, u_{t}=u$.

$$
\frac{c_{t+1}^{1}-c_{t}^{1}}{c_{t}^{1}}=\frac{c_{t+1}^{0}-c_{t}^{0}}{c_{t}^{0}}=\frac{\bar{n}_{t+1}-\bar{n}_{t}}{\bar{n}_{t}}=\bar{g}
$$

where $g_{t+1}=g_{t}=\bar{g}$.

Proposition 4: according to Definition 2, the balanced growth rate of the economy, $\bar{g}$ must equal the fecundity rate, $\bar{n}$ thus can be expressed such that

$$
\bar{g}=\left[\rho+\frac{b\left(B-u_{t}-\Delta^{1}\right)}{\left(1+\theta^{1}-v\right)(1-b)} \frac{1}{k}\right] /\left[\bar{\rho}-\frac{\Delta^{0}}{a \delta b(1-s-v) A k^{b-1}}\right]
$$

(See Definition 2 and Proposition 3 for proof).

We adopted the assumption of the equality between the growth rates of the population and of the economy since the model adopt a competitive market environment a great characteristic inside the major neoclassical growth models. Therefore per-capita physical capital, the bequest and the cost of education increase the economic growth rate. The last variable quoted tends to increase in this economy which according to the recent literature on the subject will lead to the choice of the quality rather than the quantity, thus make demographic transition yield and increase the long run economic growth rate.

Definition 3: according to Proposition 2, the economic performance, EP is defined by $E P=H_{t}^{1} \theta^{1}\left(g_{t+1}+1\right)$ which according to Definition 2 is therefore, in the long run, defined such that, $E P=H_{t}^{1} \theta^{1}(\bar{g}+1)$. 
Proposition 5: according to Definition 3, the long run in economic performance promotes women labor force participation, $\theta^{\mathrm{l}}$ associated with her husband human capital, $H_{t}^{1}$ the whole is expressed such that

$$
E P=\Phi H_{t}^{1} \theta^{1}
$$

where

$$
\Phi=\left(1+\frac{\left[\rho+\frac{b\left(B-u_{t}-\Delta^{1}\right)}{\left(1+\theta^{1}-v\right)(1-b)} \frac{1}{k}\right]}{\left[\bar{\rho}-\frac{\Delta^{0}}{a b \delta(1-s-v) A k^{b-1}}\right]}\right)
$$

The proof of Proposition 4 consists on replacing Equation (22) inside the definition of $E P$ given by Definition 3. Therefore, the economic performance, $E P$ depends positively on human capital accumulation stock, $H$, per-capita physical capital associated to some other parameters such that women labor force since we assumed the non educated women don't work but live with their husband income. Since the educated women increase in the system, the $E P$ increases too. Thus the main result provided by the model is the promotion of women work, indeed fecundity reduction since educated and early maternity are non compatible. Consequently, the main result highlights is human education promotion that we'll discuss in the following sections. In the following sections we'll discuss early fecundity inconvenient both for the women and for the economic growth rate, polygamous cost and poverty, marriages concept in Congo. Poverty generated yield to moral hazard and corruption in government institutions. Early fecundity can be viewed by the exclusion in the society since it is not linked to the labor market. Whereas polygamous choice of life generates cost highlights by $\Delta^{i}$ for $i=0,1$ and tends to reduce both the agent income and the national revenue as well as yield to reduce skills since the education becomes too costly for the single father.

\section{Early Fecundity Inconvenient}

Equation (17) gives the fecundity of the educated woman and we can see that, the procreation depends positively on the marginal propensity to save,

$\beta / 1+\alpha+\beta$ the difference between the assortative mating and the fecundity rate, $\rho$ the elasticity of human capital i.e. the education attained, $b$ the cost of raising children, $V$ and the bequest to leave and acts negatively on per-capita physical and human capital ratio, $k$ other financial duties, $\Delta^{1}$ which represents cost related to additional wives and children. Finally the wage rate income of the woman decreases the number of children she chooses to have. Therefore, education decreases the fecundity rate and may lead to demographic transition over time.

Equation (20) expresses the fecundity level of the non educated woman such as it is an increasing function of the marginal propensity to save, $\beta / 1+\alpha+\beta$ 
the difference between the "assortative mating" and the fecundity rate, $\bar{\rho}$ but in contrast to the above case, here the non educated woman tends to increase her fecundity level with higher income, $\delta$ whereas the educated woman tends to decrease her fecundity level with skills increase or income increase viewed through, $\theta$.

Proposition 6: according to Equations (15) and (17), fecundity is an increasing function of income for the non educated woman, and it is a decreasing function with income for the educated woman, therefore there exist a threshold education level, $\bar{e}^{*}$ where the two kinds of women fecundity equalize (see the Figure 1).

The main inconvenient of early fecundity is inequality generated among the both kinds of women and with men in income which reduces the probability of the girl who face early maternity to be married and drives the girl to poverty and social dependence. Therefore, she is led to accept to be a wife of a polygamous man and face a risk for her children not to be skilled and keeps the poverty vicious cycle to settle. When looking for money because of poverty generated by non sufficient income to raise the family, the young girl's aim is thus to get married but unfortunately faces, early fecundity than worsen poverty since she stays home in charge of the parents whom finally have to raise additional children, thus deteriorates more the family income. Indeed poverty creates a feedback effect that drives the concerned women to hidden unemployment caused by skill absence, thus social exclusion. The process may repeat again and again, thus the feedback effect of poverty yields oscillatory path that worsen the initial situation since the off-spring born remain parental support like the mother, thus render the situation worse than before since the pregnancy process is spent inside the parental house, thus the grand children gets inside the low parents income too. According to Proposition 5 result, the demographic transition in poorest countries consist on the establishment of the threshold level in education, so that fecundity level stability may settle and yield higher quality children rather than the quantity since the women are driven massively in the labor market after a successful human capital accumulation.

\section{Polygamous Cost}

The wealth of the educated agent, $\mathrm{W}$ can be viewed as the sum of Equations (15) and (16) expressed such that

$$
W^{1}=\left(\frac{1+\alpha}{1+\alpha+\beta}\right)\left[\frac{\rho}{b}\left(1+\theta^{1}-v\right)(1-b) k+\left(B-u-\Delta^{1}\right)\right]
$$

Therefore, for the skilled educated agent the polygamous cost including multiple wives and children associated expressed by $\Delta^{1}$ is such that when it increases, the wealth reduces. Indeed, if $\Delta^{1}>B-u$ then the cost is too high for the agent to leave bequest to the children, thus human capital accumulation for all the children is difficult because it is too costly. The children are thus unable to accumulate human capital then must remain non college educated in contrast to 


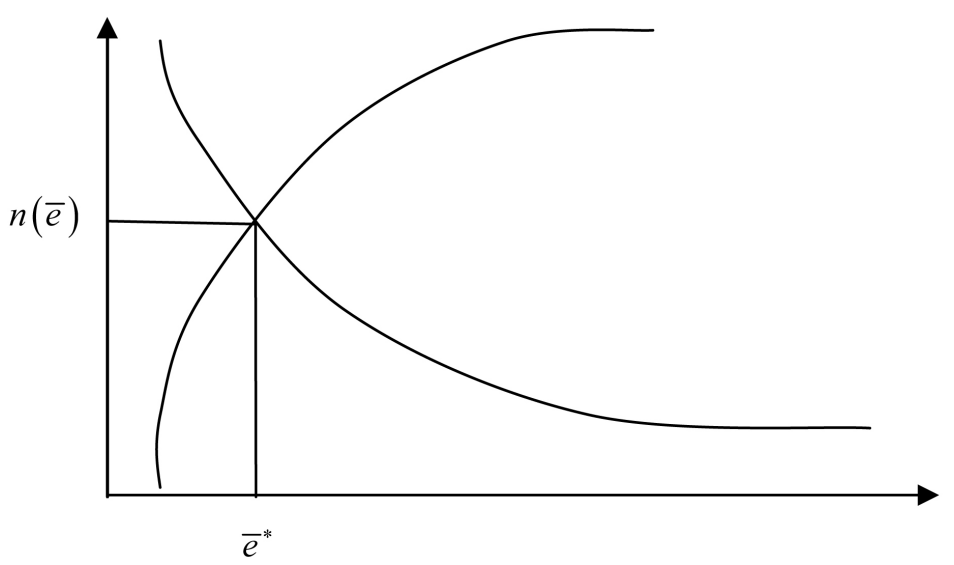

Figure 1. Highlights the intercept of the fecundity curve of non educated woman (increasing) versus the educated woman (decreasing).

his parent. Consequently multiple wives and the children associated lead to the eviction of the development since it raises the risk of human capital lack in expanding unskilled labor inside the economy since per-capita income family needed to face important duties is not high enough. The economy accumulates unskilled labor that causes a fall in the concept of social inheritance of the children from their parent job qualification. If $\Delta^{1}<B-u$ then the educated agent chooses not to have many kids and many wives but it is at this stage, difficult to determinate if there are some or not. Finally, if $\Delta^{1}=B-u$ then the educated agent chooses to have only one main family since the bequest and human capital cost are quite close. When $\Delta^{1}=0$, then the educated agent has only one wife and his children are issue from one mother only since $\Delta^{1}$ turns out to be positive, then the agent has more than one family to take care-of. Finally, the message addresses by that part is to notice that unemployment caused by low quality levels come from polygamous agents since it leads to the children cost increase and thus, the inability to finance human capital investment even when the father is skilled because there may not exist a bequest for all the children. That reality may explain partly the lack of high human capital needs in poorest countries where polygamous is allowed as well as when non educated woman are too much, thus also unable to imply in the quality of the children. In other way of viewing the problem is that, if the polygamous father is not rich enough to support human capital accumulation of all the children, then we have $B<u$ the offspring who is willing to accumulate human capital, must go to the financial market to have a loan to be skilled, unfortunately, he may not have access to the market, thus face inequality to the education access. Indeed in poorest countries where children cost become too high not necessarily due to the expense of life but to children plurality, then the government intervention is welcome to supplement the market failure due to cultural aspects encouraged by the government agreement on wives multiplicity. In contrast to the educated woman, the educated man may accumulate wives and children since the increase of his in- 
come yields the increase of the secondary cost and increase excess labor supply in the labor market which creates eviction in the development target according to old economic development theorists [20] [21].

$$
W^{0}=\frac{1+\alpha}{1+\alpha+\beta}\left[\bar{\rho}((1-s-v)) a \delta-\frac{\Delta^{0}}{A b k^{b-1}}\right]
$$

We can see that $\Delta^{1}$ is not correlated with $\mathrm{k}$ in contrast to $\Delta^{0}$.

For the non educated agent, the cost of wives plurality is expressed by, $\Delta^{0}$ such that the hypothesis made on the fact that they don't accumulate human capital turns out to be also the result, therefore to establish an equilibrium with the educated agent in term of wealth in order to determinate the threshold required in the number of children equilibrium which yield to the possibility to make them receive education we assume the wealth of the both agents to be equal in the long run.

To conclude on the two kind behaviors in polygamous choice, we try to understand what motivated that choice in order to view its incidence on the balanced growth path. For that to be viewed, we settle at the optimal locus where the wealth may be zero because of the cost generated by multiple wives and children, i.e., if $\Delta^{0}=\frac{b a \delta(1-s-v) \bar{\rho}}{k^{1-b}}$ then the polygamous cost is a decreasing function of per-capita capital ratio, $k$ and doing the same thing for the educated agent, we find that, $\Delta^{1}=\rho b^{-1}\left(1+\theta^{1}-v\right)(1-b) k+(B-u)$ is an increasing function of the ratio of human and physical capital, which means that compare to the previous equation, three things can be observed: the rich mostly face polygamous than the poor does, careless about the cost generated than the poor and he is more attractive than the poor is in regard to the woman offer of marriage because he matching more with her needs. Indeed making the above two functions equal, yields a threshold level allowing those cost not too grow too much because of the eviction caused in the economy as quoted earlier.

Proposition 7: because the polygamous cost of the rich is an increasing function of per-capita capital stock and a decreasing function of per-capita capital stock for the poor, there exists at least one locus on the space where the two curves meet i.e. threshold, $\Delta^{*}$ exist where the eviction in the economy generated by polygamous is stable (see Figure 2)

Figure 2 displays the stable polygamous cost which yields to eviction reduction in human capital accumulation of the offspring.

According to Figure 2, for $\Delta^{\mathrm{i}}>\Delta^{*}$ the non educated agent incentives to marry several wives is over in contrast to the educated agent who is able to face poly-gamous costs, thus in the society, polygamous agent win a wage rate income higher than the threshold and is more willing to choose polygamous marriages than the poor or the non educated agent. Indeed Pareto optimality locus exists in polygamous behaviors.

We can find a the equilibrium which making, $\Delta^{0}=\Delta^{1}$ i.e., 


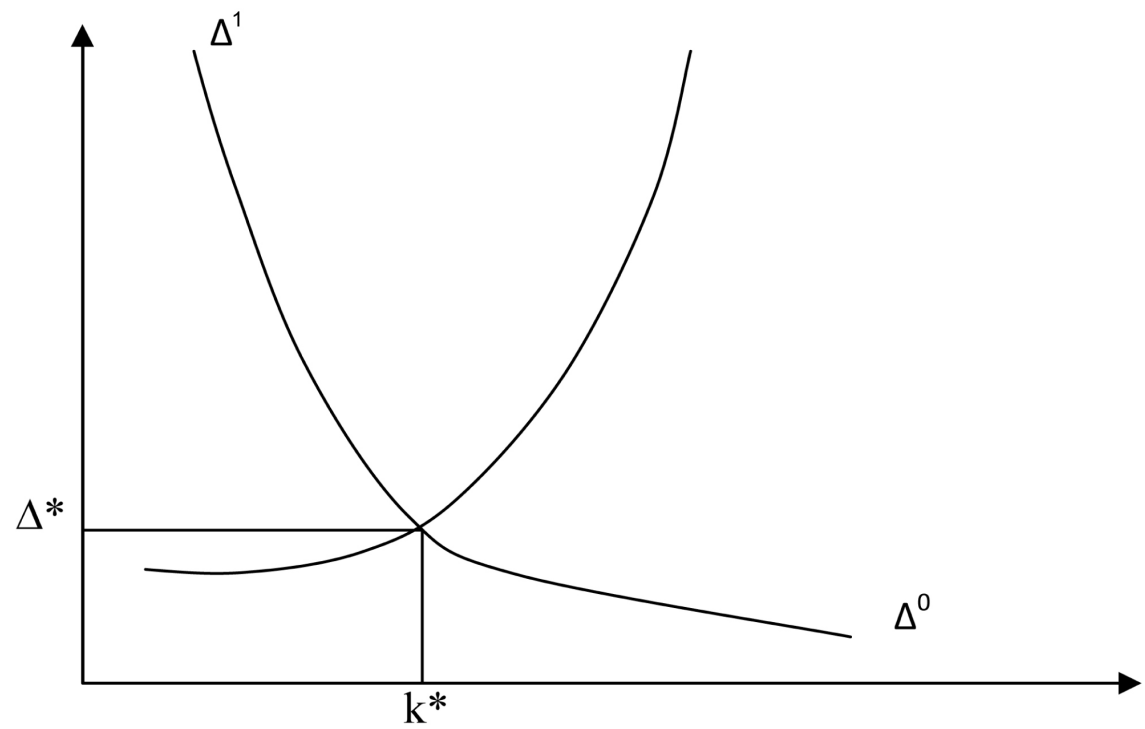

Figure 2. Displays the stable polygamous cost which yields to eviction reduction in human capital accumulation of the offspring.

$\rho b^{-1}\left(1+\theta^{1}-v\right)(1-b) k+(B-u)=\frac{b a \delta(1-s-v) \bar{\rho}}{k^{1-b}}$ therefore the solution exist since $B-u=\varepsilon>0$ assuming $\varepsilon=\varepsilon(k)$ it yields one stable solution, $k^{*}$ defin$\operatorname{ing} \Delta^{*}$.

\section{Marriages Concepts}

The multiple wives choice process is done through the mating function of the respective educated and non educated agents respectively expressed such as follow

$$
\begin{gathered}
M\left(e, e^{*}\right)=\mu_{0}(1-e)\left(1-e^{*}\right)-n_{t}^{0}+\mu_{1}\left(e e^{*}\right)-n_{t+1}^{1} \\
M\left(a, a^{*}\right)=\mu_{0}(1-a)\left(1-a^{*}\right)+\mu_{1}\left(a a^{*}\right)-n_{t}^{0}
\end{gathered}
$$

We assume $e$ attempt to match with $e_{1}^{*}, \cdots, e_{4}^{*}$ wives whereas the non educated agent, $a$ attempt to do the same thing with $a_{1}^{*}, \cdots, a_{4}^{*}$ depending on $M$.

Therefore we may have $M\left(e, e_{1}^{*}\right), M\left(e, a_{2}^{*}\right), \cdots, M\left(e, a_{4}^{*}\right)$ (the first wife of the educated agent is educated in contrast to the others) or $M\left(e, a_{1}^{*}\right), M\left(e, a_{2}^{*}\right), \cdots, M\left(e, a_{4}^{*}\right)$ (the first wife of the educated agent may not be educated like the others) in contrast $M\left(a, a_{1}^{*}\right) \succ M\left(a, a_{2}^{*}\right) \succ \cdots \succ M\left(a, a_{4}^{*}\right)$ (The non educated agent always marry non educated younger wives).

If there exist $i$ such that $\Delta^{\mathrm{i}}>\Delta^{*}$ then $M\left(a, a^{*}\right) \rightarrow M\left(a, a_{i}^{*}\right)$ for $i \leq 4$ and we may have $M\left(e, e_{1}^{*}\right) \succ M\left(e, a_{2}^{*}\right) \succ \cdots \succ M\left(e, a_{4}^{*}\right)$ (which means that education level decreases with the wife rank and is substituted by younger wives over time) and the educated agent may also marry non educated wives who are younger with the rank hold i.e. $M\left(e, a_{1}^{*}\right) \succ M\left(e, a_{2}^{*}\right) \succ \cdots \succ M\left(e, a_{4}^{*}\right)$.

Indeed, the non educated agent chooses his non educated wives until the cost crosses the threshold of unsustainable locus where quantity highly increase and 
create excess unemployed labor in the market, therefore the government intervention to cease the eviction must lead to the promotion of women labor participation increase so that inequalities among women will decrease as we fixed the fact that educated women never face polygamous and have less children, the more education the women will receive the less polygamous propositions they will accept, so that their entering in the labor market will reduce quantity and quality will increase so that polygamous will decrease, excess labor supply won't settle in the country ensuring development.

\section{Moral Hazard and Corruption}

Corruption is a behavior which deviates from formal duties of public role because of private regarding (personal, close family, private clique) pecuniary status gains; or violates rules against the exercise of certain types of private regarding influence. Corruption is motivated by poverty, productive capacities low technology and sustainability matters in developing countries while low labor productivity is mostly the resulting effect of human capital investment absence specifically in Africa. Institution imperfection is evaluated to up to $55 \%$ in Latin America against 45\% - 85\% in Easter Asia and 80\% in Africa [22] [23]. Mbaku [24] emphasizes the important role that institutions have in corruption control and he recommends reconstructive democratic constitutions as a development tool.

According to National Commission of United Nations for Africa, 52\% of people live actually with less than $1 \$$ per day. Extreme poverty represents $43 \%$ of urban population against $59 \%$ of rural population, poverty concerned 217 millions of people in 1987, 291 millions of people in 1998 and 310 millions of people in 1999 in level terms and the World Bank Millennium Development goal, i.e., cutting poverty in half still not reached in 2016. The optimality of the equilibrium assumes the perfect information, therefore if the information as a strategic character, then the agent who use it for their own profit violates the first Arrow-Debreu welfare theorem, i.e., the equilibrium is no more Pareto optimal. Recently, Georges Akerlof and Joseph Stiglitz measured the power of this fact that we evocated here as the cause of moral hazard. Since polygamous leads to excess unemployed labor due to low education levels so that the firms are unable to find the skills they need conjugated with the fact that spending caused by a big family need is too high compare to the funds detained agents are likely not to reveal information in their concern in order to win money. Skills detained are not true most of the time to work at any price since poverty settled in such a way that it becomes common to choose not to reveal the information. So that when this behavior is associated with the labor market, it is difficult to keep a job so as being cut with poverty becomes hard. In conclusion, in an environment where prevail polygamous leading to excess labor supply, the government intervention is needed because the welfare theorem is not validated, market failure is introduced and moral hazard dominates the relationships. 


\section{Social Status and Development}

Proposition 8: the intergenerational social status is a dynamical process with four steps which are social status (OA,OC) inheritance, social status regression $(O A G, O F E)$, high social status $(O A B, O C B)$ and poverty status (OGK) or may increase and reaches the highest levels or may converge depending on parental polygamous degree.

(See Figure 3 for proof).

Finally, in Congo the social status of the parents is not a prerequisite of the success of the off-spring social status like predict the standard sociological analysis.

OAG: Intermediary zone of poverty and social status equilibrium.

OA: Social status intergenerational equality locus for the non educated.

OC: Social status intergenerational equality locus for the educated.

OK: Famine locus.

OEF: Social status regression zone.

A

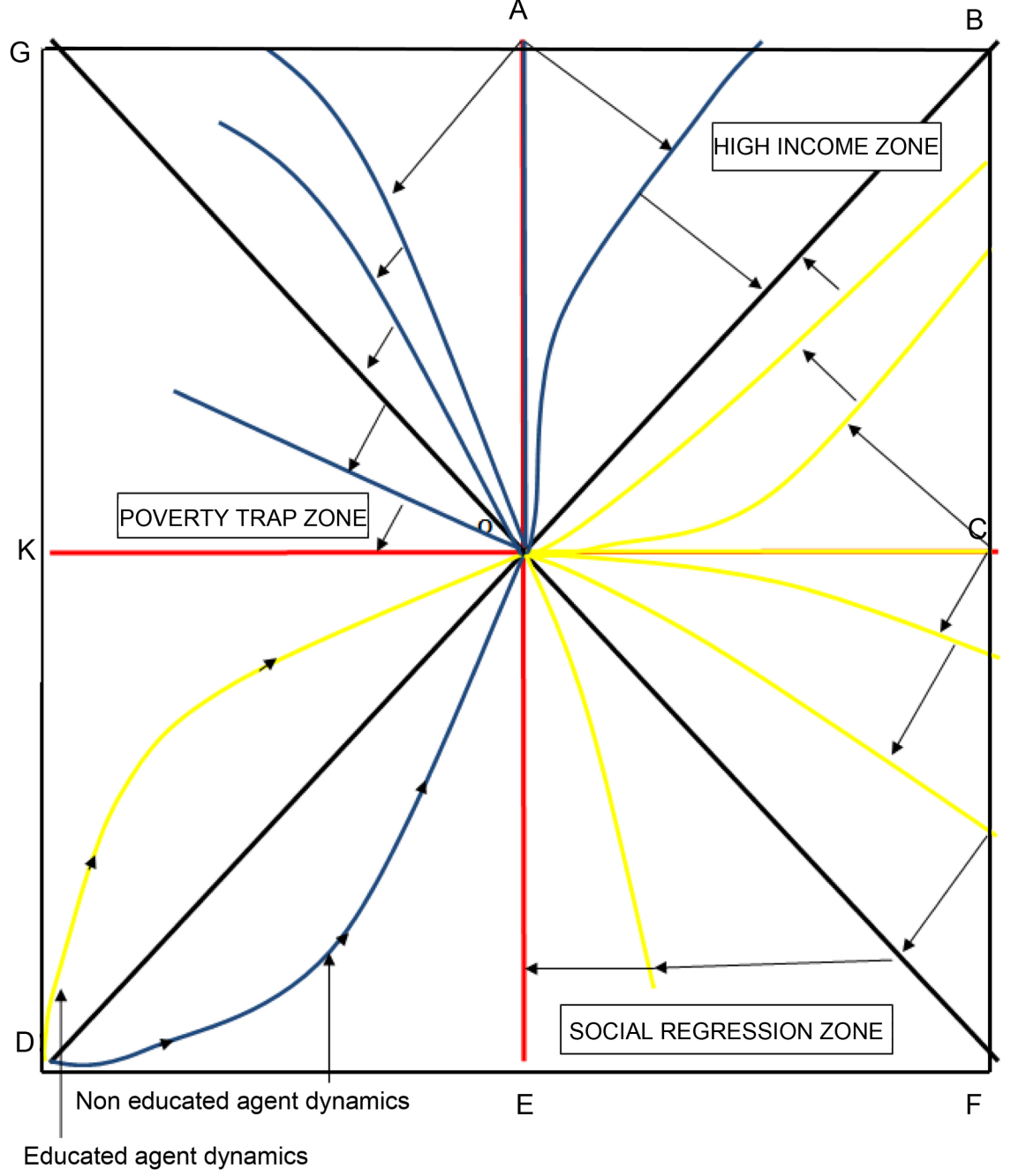

Figure 3. Summarizes the analysis conducted. 
OB: Convergence locus.

OCF: Social status intermediary zone for the educated.

Proposition 9: the society highlights convergence and catching up possibilities in social status term among heterogeneous social classes as well as poverty and famine caused by unsustainable financial support needs for the polygamous families to leave.

According to Figure 3, there is a convergence in social status (SS) term highlights by the solid line $\mathrm{OB}$ (the locus) which means that an agent born from a non educated agent and the one born from an educated agent may converge in SS term since being known as a rich man raise high financial charges such that the descendants can't beneficiate from their parent income fully. OA which is the non educated child family when facing low family charges, may tends to $O B$ and $\mathrm{OC}$ which is the educated child family when facing low family charges, may tends to $\mathrm{OB}$ too therefore $\mathrm{OA} \rightarrow \mathrm{OC}$ (convergence). Indeed we may have, $\mathrm{OA}=$ $\mathrm{OC}=\mathrm{OB}$ which is a catching up. The whole expresses social ascension specifically for the agent with monogamous father i.e. who face $\Delta^{i}<\Delta^{*}$. The yellow line expresses the agent from educated father but when polygamous is chosen by the father i.e. $\Delta^{\mathrm{i}}>\Delta^{*}, \mathrm{i}=1$, the yellow line shift down, OCF and may converge toward non educated zone, ED with the number of his father wives. Otherwise when the father is monogamous, $\Delta^{1} \leq \Delta^{*}$ then the yellow line crosses the origin (O) and may settle at the equality social status position along OC or rises more, i.e., up until the reach of the highest social status position, $\mathrm{OB}$ where he may meet other agent from different social classes origins. Similarly, the non educated agent's child dynamics may move and get inside the poverty zone, if his father is polygamous i.e. $\Delta^{0}>\Delta^{*}$ with multiple wives and since he keeps marrying wives, the social status dynamics of that agent may keep moving and get inside the poverty zone, OAG and reaches the famine zone.

\section{Conclusion}

This analysis promotes both the education and the labor force participation of the women in order to make them emancipate and generate income in the country where prevail inequality and thus, neglect in the income share. We discussed early fecundity which is incompatible with education and thus the women who face that situation are the preliminary victim of polygamous as well as poverty due to the fact that they carry excess labor supply. Therefore, the article's aim is to increase the women presence in the labor market in order to increase their social value and make them choose freely the kind of marriage they are willing to choose. Thus to increase both their age to become a mother and also to reduce their fertility rate which leads to demographic transition considered to be a mechanics of economic development. Since early development economists $^{6}$ [25] explained the Industrial Revolution of Europe, identified demographic transition and the work of the women have played a great role in de-

${ }^{6}$ This author argued that the Industrial Revolution was caused by the Enlightenment, that is by the growth of science and Analytical thinking. 
velopment, it is the same thing in Africa. Finally, the study concludes in highlighting a classification explaining social classes occurrence over time in the developing country society where polygamous exist as well as poverty caused by women's absence of work and unsustainable charges of the polygamous agent specifically how this behavior affect the economy. Indeed social class regression is caused by human capital absence which yields to corruption and moral hazard and block growth and development since firms can't find the required skills, their competitiveness is also affected. The whole analysis is summarized in Figure 3 and provides explanation to under development originated from individual agents.

\section{References}

[1] Regallia, F. and Rios Rull, V. (2001) What Accounts for the Increase in the Number of Single Households? University of Pennsylvania, Mimeo.

[2] Eckstein, Z. and Lifshitz, O. (2011) Dynamic Female Labor Supply. Econometrica, 79, 1675-1726. https://doi.org/10.3982/ECTA8803

[3] Greenwood, S.A. and Yorukoglu, M. (2005) Engines of Liberation. Review of Economic Studies, 72, 109-133. https://doi.org/10.1111/0034-6527.00326

[4] Fernandez, A. and Rogerson, R. (2001) Sorting and Long Run Income Inequality. Quarterly Journal of Economics, 116, 1305-1341. https://doi.org/10.1162/003355301753265589

[5] Fernandez, R., Guner, N. and Knowles, J.A. (2005) Love and Money: A Theoretical and Empirical Analysis of Household Sorting and Inequality. Quarterly Journal of Economics, 120, 273-344.

[6] Chiappori, P.A., Iyigun, M.F. and Weiss, Y. (2009) Investment in Schooling and the Marriage Market. American Economic Review, 99, 1689-1713. https://doi.org/10.1257/aer.99.5.1689

[7] Greenwood, J., Guner, N., Kocharkov, G. and Santos, C. (2016) Technology and the Changing Family: A Unified Model of Marriage, Divorce, Education Attainment and Married Femal Labor Participation. American Economic Journal: Macroeconomics, 8, 1-41. https://doi.org/10.1257/mac.20130156

[8] Duflo, E., Dupas, P. and Kremer, M. (2015) Education and Early Fertility: Experimental Evidence from Kenya. American Economic Review, 105, 2757-2797.

https://doi.org/10.1257/aer.20121607

[9] Galor, O. and Weil, D. (2000) Population, Technology and Growth: From Malthusian Stagnation to the Demographic Transition and Beyond. American Economic Review, 90, 806-828. https://doi.org/10.1257/aer.90.4.806

[10] Malthus, R. (1798) The Six Editions of Essay on the Principle of Population.

[11] Cervellati, M. and Sunde, U. (2015) The Economic and Demographic Transition. Mortality and Comparative Development. American Economic Journal, 7, 189-225.

[12] Eicher, T. (1996) Interaction between Endogenous Human Capital and Technological Change. Review of Economic Studies, 63, 127-144.

https://doi.org/10.2307/2298118

[13] Lucas, R.E.J. (1988) On the Mechanics of Economic Development. Journal of Political Economy, 22, 3-42.

[14] Dahan, M. and Tsiddon, D. (1998) Demographic Transition, Income Distribution 
and Economic Growth. Journal of Economic Growth, 3, 29-52. https://doi.org/10.1023/A:1009769930916

[15] Ashton, T.S. (1948) The Industrial Revolution 1760-1830. Oxford University Press, London and New York.

[16] Rostow, W.W. (1960) The Stages of Economic Growth: A Non Communist Manifesto. Cambridge University Press, Cambridge and New York.

[17] Allen, R. (2001) The Great Divergence in European Wages and Prices from the Middle Ages to the First World War. Explorations in Economic History, 38, 411-447. https://doi.org/10.1006/exeh.2001.0775

[18] Allen, R. (2009) The British Industrial Revolution in Global Perspêctive. Cambridge University Press, Cambridge and New York. https://doi.org/10.1017/CBO9780511816680

[19] Mokyr, J. (2009) The Enlightened Economy: An Economic History of Britain 1700-1850. Yale University Press, New Haven.

[20] Lewis, W.A. (1954) Economic Development with Unlimited Supplies of Labor. The Manchester School.

[21] Rosenstein-Rodan, P.N. (1943) Problems of Industrialization of Eastern and South Eastern Europe. Economic Journal, 53, Article ID: 202211.

https://doi.org/10.2307/2226317

[22] Loeadholm, C. (2002) Small Firm Dynamics: Evidence from Africa and Latin America. Small Business Economics, 18, 227-242. https://doi.org/10.1007/978-1-4615-0963-9_13

[23] Burki, A. and Terrel, D. (1998) Measuring Production Efficiency of Small Firms in Pakistan. World Development, 26, 155-169.

[24] Mbaku, J. (2007) Corruption and Development. School of Economics, Weber State University Press.

[25] Galor, O. (2011) Unified Growth Theory. Princeton University Press, Princeton.

\section{Submit or recommend next manuscript to SCIRP and we will provide best service for you:}

Accepting pre-submission inquiries through Email, Facebook, LinkedIn, Twitter, etc. A wide selection of journals (inclusive of 9 subjects, more than 200 journals)

Providing 24-hour high-quality service

User-friendly online submission system

Fair and swift peer-review system

Efficient typesetting and proofreading procedure

Display of the result of downloads and visits, as well as the number of cited articles

Maximum dissemination of your research work

Submit your manuscript at: http://papersubmission.scirp.org/

Or contact jhrss@scirp.org 